\title{
Regimes of justification in the datafied workplace: The case of hiring
}

new media \& society

$1-19$

(C) The Author(s) 2021

Article reuse guidelines: sagepub.com/journals-permissions DOI: $|0.1| 77 /|46| 44482 \mid 1052893$ journals.sagepub.com/home/nms

@SAGE

\section{Lina Dencik \\ Cardiff University, UK}

\section{Sanne Stevens}

London School of Economics and Political Science, UK

\begin{abstract}
The uptake of data-driven hiring systems has introduced important questions about how decisions about who is eligible for jobs, and why, are changing. To explore this, the article draws on interviews with prominent providers of data-driven hiring systems and analyses the way they situate the provision of tools in relation to existing hiring processes, what problems they claim to solve, and the nature of the solutions they provide. While the ideological grounds of datafication have been well-established, privileging data-driven knowledge production as less biased, more objective, and with superior insights than other forms of information-gathering, in hiring, we find legitimisation frames extend to ways in which work and workers should be organised and assessed. Drawing on the notion of 'regimes of justification', we argue that such legitimisation frames in turn invoke certain normative expectations about what is just and unjust organised around a vision of the common good.
\end{abstract}

\section{Keywords}

Automation, datafication, hiring, regimes of justification, work

Processes of recruitment and hiring are central components of establishing legitimacy in the contemporary workplace. According to Boltanski and Chiapello (2005: 32), they are a prime example of the central 'tests' of capitalism that govern access to positions

\footnotetext{
Corresponding author:

Lina Dencik, School of Journalism, Media and Culture, Cardiff University, Two Central Square, Central Square, Cardiff CFIO IFS, UK.

Email: dencikl@cardiff.ac.uk
} 
regarded as more or less advantageous. Yet, how decisions are made on who is eligible for jobs, and why, is said to be changing with the advent and growth in uptake of automated hiring systems powered by data-driven tools (Centre for Data Ethics and Innovation (CDEI), 2020; Institute for the Future of Work (IFOW), 2020). Prominent employers worldwide such as L'Oreal, Coca Cola, Deloitte, and McKinsey, responsible for tens of thousands hires each year, have all started to implement such systems in their hiring process. As these companies and many others are experimenting with innovative new technologies that rely on the automated processing of data, there are questions about the nature of transformations taking place in how candidates apply for jobs and why they get selected. These questions have only become all the more pressing with the acceleration of a move to life 'online' brought about by the COVID-19 crisis that has advanced a growing reliance on tools and platforms in shaping the terms upon which the hiring process takes place and, with that, what it means to be assessed and found suitable for a job.

The advent of automated and data-driven hiring systems has started to garner critical attention from researchers who have explored the implications of these technologies, particularly with regard to issues such as discrimination, accountability, and transparency (Ajunwa and Greene, 2019; Bogen and Aaron, 2018). Such accounts provide important insights into the mechanisms of these technologies and the way they are situated in relation to wider trends within the workplace. In particular, they point to significant affordances that automated hiring systems are claimed to provide for employers and the historical conditions out of which they have emerged. Much of this has been garnered from industry material and company documents, but often without reflections from the actual providers of these technologies on how they understand and position the use of such tools in the automation of various aspects of the hiring process. This is an important component of critically interrogating the advent of datafication in hiring as it compels us to consider how data-led processes spread and how data-informed knowledge is sought to be legitimated (Beer, 2019). We especially consider this a useful perspective for exploring the contested terrain of what it means to be qualified for a job. That is, the extent to which the datafication of hiring contributes to the solidification of a particular ethos and organisation of work(ers) through the establishment of new procedures, processes, or, to follow Boltanski and Chiapello: 'tests'.

In this article, we consider this question by drawing on interviews with eight prominent industry providers of data-driven tools for hiring used in the United States and Europe. In what is still a relatively small and nascent industry, these interviews provide a rare insight into the way providers situate data systems in relation to problem-definitions and solutions in hiring. To contextualise our analysis, we draw on the work of Boltanski (Boltanski and Chiapello, 2005; Boltanski and Thévenot, 2006) who discusses recruitment as an example of central 'tests' in capitalism that govern the distribution of persons between positions of unequal value and the more or less just nature of that distribution (Boltanski and Chiapello, 2005). Importantly, tests always express wider normative claims and frameworks, and the transformations or consolidation of tests show how normative claims emerge, stabilise, or change to establish a 'regime of justification' in the face of a plurality of interpretations of social reality (Boltanski and Thévenot, 2006). 
The process of hiring is a highly contested terrain and as different interpretations, assertions, and practices around hiring emerge, the specific claims data-driven hiring tools are based on shed light on shifts in what is considered just social selection. Analysing the claims made by providers of data-driven hiring tools therefore illustrates in part how underlying justification regimes for social dynamics in capitalism are being actively shaped. As we go on to argue, while the ideological grounds of datafication, or 'dataism' (Van Dijck, 2014), have been well-established, privileging data-driven knowledge production as less biased, more objective and with superior insights than other forms of information-gathering, in hiring, we see legitimisation frames extend to ways in which work and workers should be organised and assessed. We understand this development as furthering particular aspects of social selection and worth that is bound up with flexibilisation and individualisation captured in an emphasis on job 'fit' that Boltanski and Chiapello (2005: 98) saw as key trends of neo-management. In this sense, datafication and the justifications for data-driven tools in hiring made by providers are part of broader shifts in the way capitalism is continuously negotiated and stabilised.

\section{The 'test' of hiring}

The premise of the concept of test is rooted in Boltanski and Chiapello's (2005) understanding of capitalism as relying upon the presence of critique that shapes what they describe as the 'spirit' of capitalism. Capitalism is conceived here, in Weberian fashion, as a system driven by 'the need for the unlimited accumulation of capital by formally peaceful means' (Budgen, 2000), that is fundamentally absurd and amoral. Never just advanced on the basis of pure profit-orientation, capitalism must incorporate a moral orientation towards justice to be legitimated: '[capitalism] can rely on a number of shared representations - capable of guiding action - and justifications, which present it as an acceptable and even desirable order of things: the only possible order, the best of all possible orders' (Boltanski and Chiapello, 2005: 10). This spirit can justify the conditions in which capitalism secures the actors required for profit creation. Boltanski and Thévenot (2006) outline a number of different 'regimes of justification' in this regard, but here, we use regimes of justification in more general terms to focus on the way the 'spirit of capitalism' is supported by more or less consistent convictions around worth, values, and what defines the common good. These regimes are not static but are vulnerable to critique. If critique succeeds in surfacing contradictions and is considered valid, it prompts the deployment of moral justifications, as expressed in practical terms of justice. In order to contend with critique, the response is often a strengthening of institutions, producing law, agreements, or procedures that set the conditions within which some activities are considered legitimate (acceptable for the actors involved) - what they refer to as 'tests'. In short, capitalism and its critique interactively shape definitions and categorisations of the world. Tensions around such definitions and categorisations are often resolved through tests.

In their analysis of shifts in management discourse from the 1960s to the 1990 s, Boltanski and Chiapello (2005) identify recruitment as one of such tests through which the 'social selection of people is conducted' (p. 32). Processes of recruitment and hiring are in this sense expressions of shifts in capitalism and responses to critique needed to 
secure legitimacy. As they argue, often, responses are focused on local and small-scale displacements rather than challenging established tests head-on which would be too costly, especially in terms of legitimacy. On this basis, they see ongoing transformations in recruitment and hiring processes as a continuous negotiation of social conflict that seeks to solidify parameters for the legitimate organisation of work. Efforts towards 'flexibilisation' in advanced capitalist societies, for example, have included the wide normalisation of temporary work with fast turnovers considered essential (Hyman, 2018). This has put more pressure on quick, efficient, and continuous hiring, and changed the nature of vacancies from lifetime employment in which $90 \%$ of vacancies were filled by promotion or moving existing staff, to the overwhelming reliance on external hires for job-openings today (Cappelli, 2019). Less internal mobility means hiring efforts involve functions on different levels and make it more specific and harder to fill vacancies (Boltanski and Chiapello, 2005; Lussier, 2018).

In addition, there has been an overarching trend towards outsourcing different tasks and services that also includes the increased outsourcing of hiring to external parties (Cappelli, 2019; Ployhart, 2006). This has been accompanied by a concerted shift in Human Resources Management (HRM) from the collectivism of management-trade union relations to the individualism of management-employee relations. Such a shift is said to have brought with it a greater emphasis on a 'mutual gains' approach premised on a relation between employee commitment and organisational performance made possible during a time of declining trade union membership, increased globalised competition, and economic restructuring (Sisson, 1990; Wilton, 2016). Gooderham and Brewster (2003) see this as a growing 'Americanisation' of personnel development that has taken hold in Europe and the United Kingdom, in particular, with the aim to increase individual flexibility and employee self-regulation of quality control by also attaching wages to individual performance and competency rather than to jobs.

However, as Boltanski and Chiapello (2005: 32) remark, hiring processes are often vulnerable to critique and continuously contested as inefficient and unjust. For example, the sharp increase in the volume of applications due to flexibilisation has led many organisations to base their selection of candidates on crude criteria such as elite universities - which has been shown to not only have little predictive value in relation to job performance, but is also linked to discriminatory outcomes (Bertrand and Mullainathan, 2003; Oreopoulous, 2009; Thijssen et al., 2019). The contradiction between meritocratic ideals and persistent discrimination has been particularly prominent in hiring with studies from both the US and European contexts illustrating the extent to which ethnic minorities are significantly less likely to receive positive responses from an employer than their otherwise identically qualified White peers (Di Stasio et al., 2021; Pager, 2007; Quillian et al., 2017). Furthermore, research points to consistent issues with efficiency in hiring, such as time to fill a vacancy (Ployhart, 2006), information barriers that prevent verification and increase costs (Jeske and Schultz, 2016), or gaps between personal preferences about a job and actually attained job characteristics (Gesthuizen and Dagevos, 2008), all of which impact productivity. Indeed, industry material will frequently point to a high 'failure rate' in hiring, in some contexts, close to 50\% (Cappelli, 2019; Sullivan, 2017). 
It is within this conceptual framework and historical backdrop, we situate the more recent turn towards data-driven technologies used in hiring as an extension of the kind of negotiation outlined by Boltanski and Chiapello in establishing a regime of justification operationalised through a series of tests. While transformations in hiring are one component of the ways in which legitimacy is pursued and established in capitalism, we see it as emblematic of the premise upon which data-driven knowledge and data-driven processes are being advanced in the workplace and society more broadly. As we go on to argue, the claims made by providers of data-driven hiring tools are indicative of a longer term shift in how 'the selection process governing differential distribution' (Boltanski and Chiapello, 2005: 32) is justified in contemporary capitalism.

\section{Hiring and datafication}

With the crisis that has emerged out of the COVID-19 pandemic, debates about platforms and data infrastructures are now a key component of how we think about the nature of work. The emphasis on remote working has seen the flourishing of a software industry that provides various applications that promise to take on a string of managerial functions in this new environment (Trade Union Congress (TUC), 2020). Yet, as we have noted earlier, the integration of these technologies was already well underway and has emerged in the context of key trends in neo-management. Employee monitoring software, performance assessment tools, productivity analytics, and more are all part of a suite of technologies that make up what can increasingly be seen as the datafied workplace (Sánchez-Monedero and Dencik, 2019). This development is part of an ongoing transformation in how work is directed, evaluated, and rewarded (Kellogg et al., 2020). With regard to hiring, Ajunwa and Greene (2019) trace the advent of automated hiring platforms from the job boards that appeared in the early 1990s through to the advent of document-scanning software in the late 1990s to the more recent platformisation of automated hiring systems that seek to provide integrated solutions that imagine 'a seamless flow of employee data from the time they become interested in the firm to the time they leave it' (p. 19).

While early advancements in 'eHRM' or 'virtual HRM' were attractive to companies for being conducive to structural changes and positing solutions to some of the challenges in the hiring process (Galanaki, 2002), the advent of big data and artificial intelligence (AI) has provided a renewed impetus for computational infrastructures to be at the forefront of transformations in hiring. It coincides with the field becoming more strategic in response to the growing complexity of hiring and the proliferation of demands put on workers as they operate in more flexible settings (Aroles, 2019). The popularity of 'People Analytics' (PA) within organisations, for example, is evidence of a strong incentive to 'measure' individual employee features, informed also by a turn to behavioural science (Tursunbayeva et al., 2018). Different types of data-intensive software applications have been taken up across the so-called 'hiring funnel', from sourcing to screening, interviewing and selecting candidates (Bogen and Aaron, 2018). Beyond resumes, professional networks such as LinkedIn alongside a proliferation of social networking platforms dedicated to specific industries, trades, or professions have been significant for creating data sources that facilitate advertising, searches, and filtering of 
potential candidates (Hurrell et al., 2017; McDonald and Thompson, 2016). In many cases, these are complimented by additional data collection through assessments such as games or questionnaires integrated into hiring platforms. These data are often used to create predictive tools that rely on machine learning to perform tasks such as classification, scoring, ranking, or recommendations, familiar in other machine-learning domains (Sánchez-Monedero and Dencik, 2019). Automated tools might include recommender systems based on hybrid collaborative filtering methods to capture job seeker and recruiter preferences, tools used to filter and identify the most promising candidates, and analytics dashboards used to select candidates and generate ad hoc job offers (IFOW, 2020). These are frequently optimised for an algorithmic specification of organisational 'fit' that relies on abstracting candidate profiles in relation to historical data of the company and/or top performers for a specific role (Ajunwa and Greene, 2019; SánchezMonedero et al., 2020).

Kellogg et al. (2020) situate the widespread implementation of algorithmic technologies in organisations within the 'contested terrain' (Edwards, 1979) of organisational control in which algorithms are a major force in allowing employers to reconfigure employer-worker relations of production within and across organisations. Algorithmic management, they argue, including the use of automated hiring tools, serves as a contrast to past forms of technical and bureaucratic control through facilitating more comprehensive, instantaneous, interactive, and opaque forms of control at the same time as securing a share of capital of workers' exertions. In hiring, for example, algorithms serve to increase the scale and reduce the resources needed for the fast turnover of workers and to address recruitment across different levels of skill. Furthermore, Ajunwa and Greene (2019) argue that automated hiring is advanced on the basis of particular claimed affordances that respond to broader shifts in orders of capitalism. In particular, they identify these as loss prevention, reduced bias in hiring, reduced time spent hiring, and increased retention rates. These collectively circulate around a 'master theme' of 'the reduction of friction in the labour market, by fragmenting workers into discrete skills and dispositions' (Ajunwa and Greene, 2019: 78). While such claims do not necessarily play out in practice they serve as powerful discourses that approach workers as human capital, able to be ported smoothly between tasks and locations.

In this article, we build on these insights with a specific view to extrapolate how datadriven hiring tools are justified by those who provide them to secure their use as legitimate. While there is emerging research on the trend of datafication in the workplace, and on algorithmic management structures, in particular, we know little about how the actors developing and providing these technologies define and frame the tasks they claim to be fulfilling. As Beer (2019) argues, to understand the implications of datafication, we need to gain a greater understanding of the industry that has emerged around data, specifically how data-led processes spread and how data-informed knowledge is legitimated. Similarly, Gillespie (2014) notes that a sociological inquiry into algorithms should aspire to include the social process by which this 'knowledge machine' is made into a legitimate system, 'to see how these tools are called into being by, enlisted as part of, and negotiated around collective efforts to know and be known' that should also remind us that algorithms are now a communication technology. That is, like broadcasting and publishing technologies, they are 'caught up in and are influencing the ways in which we 
ratify knowledge for civic life' (Gillespie, 2014: 170), but organised more computationally than any medium before. The pursuit of legitimisation is therefore important not only for understanding the significance of datafication in hiring, but in a broader sense undergird how practices are entrenched and stabilised within developments and transformations of capitalism (Boltanski and Chiapello, 2005).

\section{Method}

As a way to examine automation and data systems in hiring, we are interested in how these technologies are described and contextualised by actors seeking to advance their uptake in the workplace. In particular, we seek to address a gap in research based on critical engagement with the actual providers of tools used in workplaces to get an understanding of how they approach issues pertaining to the intersection of hiring and datafication. There are many different forms of automation tools in the hiring process, but we focus here on providers of the more recent data-driven systems we described earlier that often (but not in all instances) include machine-learning techniques and that tend to cater to several aspects of the hiring process, from recruitment to selection. While we rarely have access to the exact models, typically this entails using data sources from social media platforms, organisations, or online assessments (including games), in order to profile potential candidates or organisations for more targeted recruitment, faster filtering, evaluations, or identification of organisational gaps, for example, a lack of diversity (see Raghavan et al., 2020; Sánchez-Monedero et al., 2020). We were interested in how founders and senior managers themselves define the overall mission and operations of the company. As a relatively nascent and obscure industry, these actors make up a small population that can be difficult to reach for the purposes of research and often provide limited information about their workings and approach. For this explorative study, we draw on semi-structured interviews carried out with executives from eight providers of data-driven hiring tools used around the globe, including in the United States and Europe. These were selected on the basis of prominence in the field and recruited through an existing network of contacts. We were particularly interested in including providers outside of the United States as research on automation and datafication in hiring has so far been considerably US-centric. The interviews were conducted during the period of September 2019 to June 2020 in person or through video call and lasted on average 1 hour. For the interviews, we were interested in exploring topics around (1) background to the organisation and what they do, (2) the problems in hiring they are seeking to address, (3) how the tool works, (4) the nature of and relationship with clients, (5) processes of consultation in the development and assessment of the tool, and (6) perceived challenges in the field (see Appendix 1 for interview schema).

Using inductive thematic analysis, the interviews were coded according to common themes that emerged across the sample, allowing the data to structure our analysis (Braun and Clarke, 2006). We were informed by approaches that are concerned with the ways in which data are situated and contextualised in relation to existing institutions and social practices (Kitchin and Lauriault, 2015). In line with Beer's (2019) exploration of the 'data gaze', we are interested in interrogating how the data analytics industry within hiring facilitates the spread and intensification of data-led processes. As Beer (2019) notes, 
By looking at the envisioned gaze of data analytics, we are then both tapping into wider social framings whilst also revealing the programmes of knowledge and rationalizing logics that are responsible for spreading and intensifying data-led evaluations through-out the world. (p. 7)

As such, we do not seek to make claims about how technologies are transforming processes in practice but rather use the interview themes as illustrations of the way tools are sought to be legitimised as 'tests' (procedures of hiring) by providers. While there are differences in the nature of tools and services that are provided across our sample, expressed also in differences between providers in their understanding of their role in the hiring process, we focused our analysis on cross-cutting themes that illustrate how issues, problems, and solutions are framed in relation to the intersection of datafication and hiring.

\section{Findings}

The providers we interviewed are part of a growing industry surrounding the datafication of hiring. They often define their organisation as a 'software company' or 'platform' that is focused on both candidate and employer needs. One provider described it as resembling a 'customer lifecycle management system' (Company A), while another provider described their business in terms of a 'software as a service' model that stretches across different aspects of recruitment and hiring, from job descriptions to skills assessment to retention (Company G). Such an approach, in turn, suggests that relying on hiring tools in the workplace implies broader organisational transformations and new practices that are conducive to longer term transactions. The emphasis on data systems as a continuous long-term transformation in organisational practices is also evident in the way new technologies are positioned in relation to existing hiring processes. In many cases, datafication is presented as an inevitability that organisations need to get on board with:

Data is just the future. Also your internal data, the industry data, you can't ignore it, so I think this is just going to be a new standard. (Company F)

People that use data will replace those that don't. That's fairly evidenced by other industries. (Company C)

Yet, at the same time, it is clear that advancing such a vision needs to be justified as providers are confronted with challenges from organisations that are reluctant to adapt to such a narrative. As one provider put it, 'Most challenging, I think, is still the mind-set of people. Not every company here is ready' (Company F). Another one described the biggest challenge as 'changing the status quo of how we think' (Company D). This tension around the actual implementation of data systems is indicative of a significant moment in which new procedures and processes for recruitment and hiring are being established. We see this also in how existing practices in hiring are problematised by providers on terms that seek to reconfigure the nature of assessment and evaluation. We illustrate this reconfiguration through the overarching central theme of optimisation for fit that emerged from our interviews within which themes such as objectivity, bias mitigation, human interaction, and persona-centric evaluations are submerged. 


\section{Optimising for fit}

Existing problems in hiring are predominantly oriented towards difficulties with securing an appropriate 'fit' between a candidate and job. As one provider said, 'our focus is especially on greater effectiveness in hiring. People with a better fit' (Company E). Another described it as eliminating the component of 'mis-hiring' understood as 'incorrect fit' (Company A). While the meaning of 'fit' is rarely concretised, often it is tied up with both a concern with 'better candidate experience' as well as 'productive and efficient use of time' for the recruiter. In particular, the problem of mis-hires and incorrect fit is linked to the nature of or lack of informational insights about both a candidate and an employer. That is, existing practices in hiring rely on processes of information-gathering that are ineffective and can be overcome by data collection and data analytics:

Can we help people gain insights that are so hard to get at a time when I'm meeting you for the first time in an interview, saying something about how well you can do in a particular job? (Company C)

How do you create a feedback mechanism to make sure that, if you're having mis-hires, then you're understanding why that is happening and where the process is breaking? (Company A)

Importantly, issues around inadequate 'job-fit' are not defined simply in terms of a lack of information that can be overcome through more extensive data collection but in the sense that data analytics provide unique insights not possible through more established forms of assessments such as using resumes and questionnaires. The premise of most of the tools is that they are able to surface personal capacities that would otherwise go unnoticed and that this provides a better prediction of future job performance than curriculum vitae (CVs). There was in this sense an emphasis on the ability to recognise 'hidden potential' or 'raw talent' that previous forms of information-gathering would not capture:

We are using [your use of] language to discover unconscious patterns that tell us who you are, in terms your motivation, your attitude, your personality. (Company E)

Another provider described their system as being able to 'reveal the biological building blocks of human performance' (Company F). Here, there is a connection made between data analytics and cognitive neuroscience in which various behaviours and activities are turned into data points ('a model of cognition') that when analysed reveal specific characteristics ('building-blocks') of a person that they may not even be aware of themselves.

The notion that tools can better optimise the hiring process for fit based on unique insights not obtained through conventional information-gathering relies upon but goes beyond the more familiar justifications for data-driven processes that relate to objectivity and bias mitigation (c.f. Boyd and Crawford, 2012). The association between data and objectivity or bias mitigation still underpins much of how providers describe the affordances of their tools and the ability to optimise for fit: 
It's a more fair point of departure. Everybody gets assessed on the basis of the same information and that's just not the case with a traditional way of applying. (Company F)

We think the data we collect provides more objective measures of the way people actually think and process information and perform a job. (Company B)

Crucially, objectivity here is linked to both standardisation that can only be achieved through automation as well as the unique affordances of data analytics to better capture people as (potential) workers in a way existing forms of knowledge production do not. As one provider outlined, 'a resume becomes stale very quickly' whereas 'people make a lot of content about themselves online and so the solution is actually just to aggregate all of those pieces of content into one place' (Company A). Another provider made a similar point about questionnaires:

With a lot of tests, you measure skills without understanding why somebody's good at something. Or if someone has a bad score, they might just be bad at the way the tests try to measure skills. And we're actually going one level deeper . . . like basic reaction time, the extent to which you can correct a mistake just in time, the extent to which you can keep things in your working memory. (Company E)

Similarly, the presence of bias in established hiring procedures serves as an undercurrent for the need to identify new methods for fit. One provider, for example, who described their system as especially oriented towards bias mitigation identified a number of ways bias is present in current hiring practices, ranging from 'unconscious bias' to assessments that have a 'racial test scale ... that mean Caucasians perform better on them than racial minority groups', to the mechanisms used to narrow 'very large pools of applicants' that 'tend to treat certain demographic groups with a lot more preference' (Company B). In response to this, several of the providers articulated ways in which their tools work to 'de-bias' the hiring process by relying on data analytics to prioritise what is perceived as relevant information, while filtering out other information as a way to minimise the possibilities of bias in decision-making:

We work to de-bias our models, both at the beginning and the design phase, off of a reference set. So when we build our first model, we'll test it off of this reference set that we have. It's tens of thousands of users who we have demographic labels for and then that goes to the baseline assurance that our models are fair and that they don't discriminate against any demographic group. Then once the model is built for the particular role and we have made recommendations about which candidates are most likely to be a firm fit, before we pass those onto the client, we'll again make sure that the model has been fair and treated all demographic groups with parity in the assessment process. (Company B)

we don't even label on gender or ethnic background but we do check, in case studies, whether there are big differences between these groups. (Company $\mathrm{C}$ )

It is worth noting that some of the providers we interviewed also expressed clear limitations with such automation. In particular, with regard to the ways in which data and the algorithmic processing of data are also inherently subject to bias: 
[A]n algorithm is always man-made, in a first variant, so you always start with prejudice. I don't believe there is an algorithm in this world that has zero comma zero prejudice in it. (Company F)

By definition, we don't believe that training data in our space is unbiased because you would have to use existing organisation data and I'm not aware of any organisation that can prove that the way that it has acquired that data doesn't contain historic bias. (Company D)

In this sense, some of the providers sought to also limit the scope of automation in hiring by retaining the significance of human input in the decision-making process:

it's not the boss. It's not fully automated. It's a recommendation system. (Company E)

our view is that no human involvement, given the datasets that we have available to us to build machine learning tools from, is probably not the solution. (Company D)

The emphasis on this 'human-in-the-loop' aspect in the hiring process holds not only legal significance (in the EU, for example, the General Data Protection Regulation stipulates that no decision with significant legal impact should be solely automated) but also allows providers to accommodate the optimisation for fit afforded by datafication within existing practices. In most instances, providers spoke of overcoming challenges in hiring rather than radically transforming the foundation or purpose of hiring. In particular, the framing of data analytics as affording a more accurate picture of candidates is positioned as part of a broader shift in the labour market towards what is described as 'soft skills' and 'persona-centric' specification over experience and jobs in hiring processes. One provider noted,

the market trends are showing . . . that soft skills are a huge differentiation point. Especially now with the rise in automation and AI, hard skills are becoming less and less prevalent and any hard skills can be trained on the job. But having the right combination of soft skills is a major hurdle that needs to be overcome. (Company A)

Similarly, another provider said,

a big job we undertake is weaning the company off job based hiring onto skill based hiring . . So when you say to someone what does it take to be a sales person, for example, you say they'll need to be resourceful, persistent, smart, etc. (Company C)

Optimisation for fit is in that sense closely linked to a different form of evaluation:

with our methodology we ignore criteria that are usually a starting point for selection such as where did you work before? What was your background? . . . we know that job experience, for example, what have you done in the past, has a low correlation to predictions of success. (Company C)

As such, the kind of data collected through data-driven hiring systems and the way that data are processed is understood to provide insights about skills and personality 
traits that were previously absent from candidate assessments that in turn will garner a more successful outcome. This privileging of soft skills and personality in the assessment of candidates is subsumed within the problem-definition of mis-hiring based on an understanding of 'fit' that can offer data analytics as a solution in a way that extends already emerging shifts in economic stratifications and social closures. Moreover, as we will elaborate on below, it nurtures the normative expectations of such assessments advancing a better outcome for all based on an assumed relationship between personality and good job fit.

\section{Establishing regimes of justification in data-driven hiring}

The uptake of data-centric and automated systems in hiring is an important aspect of the increasingly datafied workplace. Algorithmic management structures, such as those associated with platform labour and elsewhere, have been the subject of growing scrutiny and critique. Yet, hiring can be seen to intersect with datafication on different terms than these other transformations at work in part because of the ongoing and prevalent concerns that mark the development of hiring processes. As our findings illustrate, providers of data-driven hiring systems outline significant problems that undermine the legitimacy of existing practices and present them as inherently ineffective and unfair for both employers and candidates. Advancing a business model that encompasses the entire management life-cycle, providers position their tools as a way to overcome both the ineffectiveness and unfairness of existing hiring practices that can serve a greater good in terms of productivity, job satisfaction and well-being. This is important, as it means that hiring tools should not be thought of as one-off shrink-wrap software but rather as services that bind users into long-term transactions with software companies based on constant monitoring and amendments through user analytics (Guerses and Van Hoboken, 2017). Such a political economy entrenches the position of providers within processes in the organisation of work and elevates the significance of how they frame problems and solutions in relation to such processes.

We have illustrated the framing advanced by providers through the overarching theme of optimising for fit, which extends already existing features in hiring practices oriented towards soft skills and 'cultural matching' (Rivera, 2012) but underpin them with 'objective' and 'de-biased' algorithmic calculations. The premise is framed here in terms of unique insights garnered from data analytics that are said to uncover person-specific traits and characteristics that serve as a more objective and fair basis for evaluation. Andrejevic (2019) has referred to a prevalence of a 'fantasy of framelessness' in understandings of datafication that contends that with enough data, we can escape the fallacies of narrative and interpretation (linked to qualities of the human subject) and instead achieve the 'true' account of social activities and human behaviour. In this context, the power of data analytics affords the creation of an 'algorithmic identity' (Cheney-Lippold, 2017) based on the aggregation of vast data sources as a means by which our data double can stand in for our embodied selves.

It is not the aim here to assess the validity of these claims or how a data-driven approach plays out in practice, but rather to understand the framing of hiring from providers as an expression of the negotiation around the legitimacy of hiring by invested 
actors. Providers of data-driven hiring tools need to establish legitimacy not simply on the basis of technological progress or advancement, but as new processes, or tests, for what it means to be qualified for a job. These legitimation frameworks feed into regimes of justification in which actors invoke certain normative expectations about what is just and unjust organised around a vision of the common good based on coherent vocabularies of argumentation and justification. Often legitimacy of social order is enacted through what Boltanski and Chiapello (2005) refer to as 'displacements' of tests or a 'multiplicity of micro-displacements, locally circumventing the most costly tests or those most subject to critique' (p. 35). This allows for people to be successfully committed to the capitalist process by offering modalities that invoke assurances of justice (Chiapello, 2003).

Optimising for fit is a way of overcoming central challenges on terms that can 'displace' aspects of the hiring process in such a way that responds to critique so as to retain its legitimacy. It seeks to secure legitimacy based on a regime of justification that in turn sets the parameters for how to understand and act upon problems. For example, bias in hiring is seen as an issue of flawed human judgement and lack of relevant information that positions the implementation of data-driven tools as a way to showcase action taken on discrimination. While this displaces previous processes based on resumes or questionnaires known to be imbued with bias, it may also mean that action is taken in a way that bypasses underlying causes that rely on more complex structural and collective approaches (Hoffmann, 2019). As Noon (2017) notes, 'structures are hugely important in embedding racial disadvantage, sometimes labelled institutional racism, and making organisations resistant to agendas for change'. Furthermore, there can be a temptation to ignore the often more obscured and systemic forms of discrimination that are embedded in data-driven systems (Ajunwa, 2018). This means that traditional avenues for identifying and challenging discrimination in hiring may become more difficult when these systems and their definitions of issues become the gatekeepers to employment across divergent contexts (Sánchez-Monedero et al., 2020).

Moreover, the providers we interviewed point to an advancement of data-driven hiring tools on the premise of a different form of evaluation that shifts the terms from qualifications and experience to personality and cognitive skills. Not only is this presented as a more accurate evaluation of a candidate, but is also offered as a solution to concerns about job satisfaction and retention that are established success measures in hiring (Peterson, 2005). This is a form of evaluation we also see elsewhere in the workplace with the uptake of data-based wellness programmes that link job satisfaction and retention to behavioural assessments of employees with a promise of greater employee commitment (McEwen, 2020). Such understandings of 'fitness' are intimately linked to discussions on the quantification of subjectivity that have been particularly prominent in the context of self-quantification both within and outside the workplace (Schüll, 2019). In this context, what it means to be fit for a job reinforces self-understandings in terms of persona and cognitive profiles that might add pressure to adapt (digitally traced) behaviour in such a way that suits the analytics behind such profiles. Moore and Robinson (2016) have described this trend as the emergence of the 'quantified worker' in which employees internalise the logics of the technologies used to manage and assess them. Indeed, at some universities in the United States, students are being trained to optimally 
perform in job interviews using AI by changing their use of words and facial expressions (Harwell, 2019).

As such, we point to the framings of data-driven hiring tools outlined by providers as expressions of a moment of both conflict and transformation in hiring that rely upon justifications that are not merely oriented towards profit but also invoke values of how work and workers should be organised and assessed. We see these as part of a process of establishing new tests, understood as procedures that require legitimacy for capitalism to function. These, in turn, we suggest, have implications for how problems and solutions are approached in relation to hiring and, moreover, what it means to be qualified for a job. While providers are only one type of actor in the negotiation of hiring, the provision of data-driven tools as a service catered to integrated management life-cycles secures a level of dependency that makes them a very significant one for critically examining transformations in relation to datafication.

\section{Conclusion}

The rapid uptake of hiring systems that rely on data collection and automation is becoming a growing issue in discussions about the intersection of new technologies and work. Much debate on the datafication of hiring has focused on the potential for these technologies to both resolve long-standing challenges as well as introduce new issues that need to be addressed. These have predominantly been centred on concerns about a lack of transparency, the accountability of decision-making, the potential for algorithmic bias, and increased information asymmetry between managers and candidates. Yet, in order to engage with the broader implications of datafication in hiring, we need to account for the ways in which the advancement of data systems is legitimated on terms that invoke particular values in relation to the meaning and organisation of work.

As a way to approach this, we have drawn on Boltanski's notion of regimes of justification that elicits the ways in which operations of capital rely upon particular legitimation frameworks that are oriented towards a vision of the common good. In particular, Boltanski and Chiapello see hiring as one of capitalism's 'tests' that need to continuously negotiate responses to critique in order to secure its legitimacy. In this context, we see the framing of data-driven hiring tools posited by providers of these technologies as expressions of such negotiations in the way that they seek to displace previous processes in hiring with new ones. While we are familiar with justifications for data-driven processes and knowledge in terms of efficiency and objectivity, we find that providers integrate such perceived affordances into a broader vision of datafication in hiring geared towards an optimisation for fit. This vision entails not only a more efficient and fairer hiring process through the unique ability of data analytics to capture people as they actually are, but also shifts the terms of what it means to be suitable for a job. It does so by extending trends of individualisation and flexibilisation towards cognitive and persona-centric evaluations as the basis of just social selection.

Situating our analysis within regimes of justification therefore allows us to consider the basis of legitimacy upon which data-driven solutions in hiring are being established as new tests in capitalism. Using interviews with providers of such technologies gives us a rare insight into the vision of the industry behind datafication in hiring and the way they 
conceive of the organisation and assessment of work and workers. Further research will need to uncover the extent to which such tests are seen as legitimate by other actors in the hiring process and the extent to which optimising for fit is transforming how and why people are hired in practice. Such research will need to engage with developments within actual workplaces and candidate experiences in order to inform how datafication is shaping collective visions of work. This is important as regimes of justification as they relate to capitalism - and the role of datafication - establish certain parameters for how we define long-standing complex social problems and what might be suitable solutions that therefore also marginalise alternative definitions. In a broader sense, we would suggest that looking at data-driven technology as new legitimate tests in contexts of contestation and the values and visions of the common good which are invoked in the process, is a valuable framework to inform research into the transformative implications of datafication for social relations at work and beyond.

\section{Acknowledgements}

We are extremely grateful to the two anonymous reviewers whose comments significantly improved the quality of the article, and to Alex J. Wood for his comments on an earlier version of this article.

\section{Funding}

The author(s) disclosed receipt of the following financial support for the research, authorship, and/ or publication of this article: The research of Lina Dencik was supported by the ERC Starting Grant DATAJUSTICE (grant no. 759903) under the Horizon 2020 research and innovation program.

\section{ORCID iD}

Lina Dencik (iD https://orcid.org/0000-0002-1982-0901

\section{References}

Ajunwa I (2018) The rise of platform authoritarianism. ACLU. Available at: https://www.aclu.org/ issues/privacy-technology/surveillance-technologies/rise-platform-authoritarianism

Ajunwa I and Greene D (2019) Platforms at work: automated hiring platforms and other new intermediaries in the organization of work. In: Greene D, Vallas SP and Kovalainen A (eds) Work and Labor in the Digital Age, Research in the Sociology of Work, vol. 33. Bingley: Emerald Publishing, pp. 61-91.

Andrejevic M (2019) Automated Media. Abingdon: Routledge.

Aroles J (2019) Mapping themes in the study of new work practices. New Technology, Work and Employment 34(3): 285-299.

Beer D (2019) The Data Gaze: Capitalism, Power and Perception. London: SAGE.

Bertrand M and Mullainathan S (2003) Are Emily and Greg more employable than Lakisha and Jamal? A field experiment on labor market discrimination. Report no. w9873. Cambridge, MA: National Bureau of Economic Research.

Bogen M and Aaron R (2018) Help wanted: an examination of hiring algorithms, equity, and bias. Upturn. Available at: https://www.upturn.org/static/reports/2018/hiring-algorithms/ 
files/Upturn\%20-\%20Help\%20Wanted\%20-\%20An\%20Exploration\%20of\%20Hiring\%20 Algorithms, $\% 20$ Equity\%20and\%20Bias.pdf

Boltanski L and Chiapello E (2005) The New Spirit of Capitalism. London; New York: Verso Books.

Boltanski L and Thévenot L (2006) On Justification: Economies of Worth. Princeton, NJ: Princeton University Press.

Boyd D and Crawford K (2012) Critical questions for big data. Information, Communication \& Society 15(5): 662-679.

Braun V and Clarke V (2006) Using thematic analysis in psychology. Qualitative Research in Psychology 3(2): 77-101.

Budgen S (2000) A new 'spirit of capitalism'. New Left Review, 1 January/February. Available at: https://newleftreview.org/issues/iil/articles/sebastian-budgen-a-new-spirit-of-capitalism

Cappelli P (2019) Your approach to hiring is all wrong. Harvard Business Review, May-June. Available at: https://hbr.org/2019/05/recruiting

Centre for Data Ethics and Innovation (CDEI) (2020) Review into bias in algorithmic decisionmaking. Report. Available at: https://assets.publishing.service.gov.uk/government/uploads/ system/uploads/attachment_data/file/957259/Review_into_bias_in_algorithmic_decisionmaking.pdf

Cheney-Lippold J (2017) We Are Data. New York: New York University Press.

Chiapello E (2003) Reconciling the two principal meanings of the notion of ideology: the example of the concept of the 'spirit of capitalism'. European Journal of Social Theory 6(2): 155-171.

Di Stasio V, Lancee B, Veit S, et al. (2021) Muslim by default or religious discrimination? Results from a cross-national field experiment on hiring discrimination. Journal of Ethnic and Migration Studies 47: 1305-1326.

Edwards R (1979) Contested terrain: the transformation of the workplace in the twentieth century. New York: Basic Books.

Galanaki E (2002) The decision to recruit online: a descriptive study. Career Development International 7(4): 243-251.

Gesthuizen M and Dagevos J (2008) Mismatching of persons and jobs in the Netherlands: consequences for the returns to mobility. Work, Employment \& Society 22(3): 485-506.

Gillespie T (2014) The relevance of algorithms. In: Gillespie T, Boczkowski PJ and Foot KA (eds) Media Technologies. Cambridge, MA: MIT Press, pp. 167-194.

Gooderham P and Brewster C (2003) Convergence, stasis or divergence? Personnel management in Europe. Journal of Business Research 17(1): 7-18.

Guerses S and Van Hoboken J (2017) Privacy after the agile turn. In: Polonetsky J, Tene O and Selinger E (eds). Cambridge Handbook of Consumer Privacy. Cambridge: Cambridge University Press. Available at: https://osf.io/preprints/socarxiv/9gy73/

Harwell D (2019) HireVue's AI face-scanning algorithm increasingly decides whether you deserve the job. The Washington Post, 22 October. Available at: https://www.washingtonpost.com/ technology/2019/10/22/ai-hiring-face-scanning-algorithm-increasingly-decides-whetheryou-deserve-job/

Hoffmann AL (2019) Where fairness fails: data, algorithms, and the limits of antidiscrimination discourse. Information, Communication \& Society 22(7): 900-915.

Hurrell SA, Scholarios D and Richards J (2017) 'The kids are alert': generation Y responses to employer use and monitoring of social networking sites. New Technology, Work and Employment 32(1): 64-83.

Hyman L (2018) Temp: How American Work, American Business, and the American Dream Became Temporary. New York: Viking/Penguin Random House. 
Institute for the Future of Work (IFOW) (2020) Artificial intelligence in hiring: assessing impacts on equality. Report. Available at: https://www.ifow.org/publications/artificial-intelligencein-hiring-assessing-impacts-on-equality

Jeske D and Schultz K (2016) Using social media content for screening in recruitment and selection: pros and cons. Work, Employment \& Society 30(3): 535-546.

Kellogg KC, Valentine MA and Christin A (2020) Algorithms at work: the new contested terrain of control. Academy of Management Annals 14(1): 366-410.

Kitchin R and Lauriault TP (2015) Towards critical data studies: charting and unpacking data assemblages and their work. The Programmable City Working Paper 2. Available at: https:// papers.ssrn.com/sol3/papers.cfm?abstract_id=2474112

Lussier K (2018) Personality, Incorporated: Psychological Capital in American Management, 1960-1995. University of Toronto. Available at: https://tspace.library.utoronto.ca/handle/1807/92089

McDonald P and Thompson P (2016) Social media(tion) and the reshaping of public/private boundaries in employment relations. International Journal of Management Reviews 18(1): $69-84$.

McEwen K (2020) Actuarial bodies: data, value, and fairness in insurance and workplace wellness programs. $\mathrm{PhD}$ Thesis, University of Toronto, Toronto, ON, Canada.

Moore P and Robinson A (2016) The quantified self: what counts in the neoliberal workplace. New Media \& Society 18(11): 2774-2792.

Noon M (2017) Pointless diversity training: unconscious bias, new racism and agency. Work, Employment \& Society 32(1): 198-209.

Oreopoulous P (2009) Why do skilled immigrants struggle in the labor market? A field experiment with six thousand resumes. Report no. w15036. Cambridge, MA: National Bureau of Economic Research.

Pager D (2007) The use of field experiments for studies of employment discrimination: contributions, critiques, and directions for the future. The ANNALS of the American Academy of Political and Social Science 609(1): 104-133.

Peterson CH (2005) Employee retention: the secrets behind Wal-Mart's successful hiring policies. Human Resource Management 44(1): 85-88.

Ployhart RE (2006) Staffing in the 21st century: new challenges and strategic opportunities. Journal of Management 32(6): 868-897.

Quillian L, Pager D, Hexel O, et al. (2017) Meta-analysis of field experiments shows no change in racial discrimination in hiring over time. Proceedings of the National Academy of Sciences 114(41): 10870-10875.

Raghavan M, Barocas S, Kleinberg J, et al. (2020) Mitigating bias in algorithmic hiring: evaluating claims and practices. In: $A C M / F A T^{*} 20$ : proceedings of the 2020 conference on fairness, accountability, and transparency. Available at: https://dl.acm.org/doi/ abs/10.1145/3351095.3372828

Rivera LA (2012) Hiring as cultural matching: the case of elite professional service firms. American Sociological Review 77(6): 999-1022.

Sánchez-Monedero J and Dencik L (2019) The datafication of the workplace. DATAJUSTICE project. Available at: https://datajusticeproject.net/wp-content/uploads/sites/30/2019/05/ Report-The-datafication-of-the-workplace.pdf

Sánchez-Monedero J, Dencik L and Edwards L (2020) What does it mean to 'solve' the problem of discrimination in hiring? Social, technical and legal perspectives from the UK on automated hiring systems. In: $A C M / F A T^{*}$ '20: proceedings of the 2020 conference on fairness, accountability, and transparency. Available at: https://dl.acm.org/doi/10.1145/3351095.3372849 
Schüll ND (2019) Self in the loop: bits, patterns, and pathways in the quantified self. In: Papacharissi $\mathrm{Z}$ (ed.) A Networked Self and Human Augmentics, Artificial Intelligence, Sentience. New York; London: Routledge, pp. 24-38.

Sisson K (1990) Introducing the Human Resource Management Journal. Human Resource Management Journal 1(1): 1-11.

Sullivan J (2017) Ouch, 50\% of new hires fail! 6 ugly numbers revealing recruiting's dirty little secret. ERE, 10 April. Available at: https:/www.ere.net/ouch-50-of-new-hires-fail-6-uglynumbers-revealing-recruitings-dirty-little-secret/

Thijssen L, Coenders M and Lancee B (2019) Etnische discriminatie op de Nederlandse arbeidsmarkt. Mens \& Maatschappij 94(2): 141-176.

Trade Union Congress (TUC) (2020) Technology managing people - the worker experience. Report. Available at: https://www.tuc.org.uk/research-analysis/reports/technology-managingpeople-worker-experience

Tursunbayeva A, Di Lauro S and Pagliari C (2018) People analytics - a scoping review of conceptual boundaries and value propositions. International Journal of Information Management 43: 224-247.

Van Dijck J (2014) Datafication, dataism and dataveillance: big data between scientific paradigm and ideology. Surveillance \& Society 12(2): 197-208.

Wilton N (2016) An Introduction to Human Resource Management. London: SAGE.

\section{Author biographies}

Lina Dencik is Professor in Digital Communication and Society at the School of Journalism, Media and Culture at Cardiff University and Co-Director of the Data Justice Lab. She is currently Principal Investigator of the project DATAJUSTICE funded by a Starting Grant from the European Research Council.

Sanne Stevens is Co-Director of the Justice, Equity and Technology Table at the Department of Media and Communications, London School of Economics and Political Science.

\section{Appendix I}

\section{Interview schema:}

1. Background to organisation and what it does

a. How many? Who does what?

b. What is your business model?

2. What problems in recruitment or hiring are you seeking to address?

a. How does your tool seek to address these problems?

b. What do you see as the strength of your specific method?

c. How does this tool benefit its users? How does it benefit the clients?

d. What are your main challenges for addressing these problems in this specific way?

e. Which specific insights considering the relationship between managers and candidates does the tool build on/are relevant in the methodology?

f. What insights around the issues of bias and exclusion in hiring inform your practise? 
3. How does the tool work?

a. What data sources does it draw from? Why? What are the challenges?

b. What kind of analysis is carried out? How did you come to this analysis?

What are the challenges?

c. What kind of variables is included? Why these variables?

4. Who are your clients?

a. How does this relationship come about?

b. What is the involvement of the client in the development of the system?

c. How is the tool adapted to client needs?

5. Do you consult anyone in the development and assessment of the tool?

a. Is the tool tested for accuracy? Who does this? How is it done?

b. What kind of impact assessment is carried out?

c. Do you collect user feedback?

d. How do you see the role of regulation? What regulation applies?

e. Role of stakeholders? (civil society, unions, associations, think tanks)

6. What are your main challenges at this moment?

a. What are the challenges for the wider field of data-driven and automated hiring?

b. What do you see are the most important developments in data-driven and automated hiring for the future? 